\title{
Safety and Activity of Sorafenib in Addition to Vinflunine in Post-Platinum Metastatic Urothelial Carcinoma (Vinsor): Phase I Trial
}

\author{
Carl-Henrik Shah, ${ }^{a, c}$ Helle Pappot, ${ }^{e}$ Mads Agerbak ${ }^{d}{ }^{d}$ Karin Holmsten, ${ }^{a}$ Fredrik Jäderling, ${ }^{b}$ Jeffrey Yachnin, $^{a, c}$ Per Grybäck, \\ Hans von der MaAse, ${ }^{e}$ Anders Ullén ${ }^{a, c}$ \\ ${ }^{\mathrm{a} D e p a r t m e n t}$ of Oncology-Pathology, Karolinska Institutet, Solna, Sweden; ${ }^{\mathrm{b}}$ Department of Radiology and ${ }^{\mathrm{C}}$ Theme Cancer, Karolinska \\ University Hospital, Solna, Sweden; ${ }^{d}$ Department of Oncology, Aarhus University Hospital, Aarhus, Denmark; ${ }^{\mathrm{D}}$ Department of \\ Oncology, Rigshospitalet, University Hospital of Copenhagen, Copenhagen, Denmark
}

TRIAL INFORMATION

- ClinicalTrials.gov Identifier: NCT01844947

- Sponsor(s): Anders Ullén
- Principal Investigator: Anders Ullén

- IRB Approved: Yes

\section{LESSONS LEARNED}

- First trial to report safety and activity of the microtubule inhibitor vinflunine plus the tyrosine kinase inhibitor sorafenib in post-platinum metastatic urothelial cancer (mUC) patients.

- A recommended phase II dose was identified for the treatment combination of vinflunine plus sorafenib, with main adverse events including fatigue, febrile neutropenia, neutropenia, hypertension, and hyponatremia.

- An overall response rate of $41 \%$ to second-line vinflunine plus sorafenib treatment in patients with platinum-resistant mUC was confirmed.

\section{Abstract}

Background. Platinum-progressive metastatic urothelial carcinoma (mUC) is a clinical challenge. The tyrosine kinase inhibitor sorafenib has demonstrated varied activity in mUC. This trial was designed to examine safety and activity of vinflunine plus sorafenib in mUC.

Methods. In addition to standard dose of vinflunine (320 or $280 \mathrm{mg} / \mathrm{m}^{2}$ ), patients received sorafenib $(400,600$, or $800 \mathrm{mg} /$ day), in a $3+3$ dose-escalation phase I design.

Results. Twenty-two patients (median age 62.5 years) were included. Five patients received vinflunine $320 \mathrm{mg} / \mathrm{m}^{2}$ and 17 received $280 \mathrm{mg} / \mathrm{m}^{2}$. The maximum tolerated dose (MTD) of sorafenib with vinflunine $280 \mathrm{mg} / \mathrm{m}^{2}$ was $600 \mathrm{mg}$, and with vinflunine $320 \mathrm{mg} / \mathrm{m}^{2}$ it was not determined, owing to toxicity. Adverse events (AEs) grades $3+4$ consisted of neutropenia (6 patients), febrile neutropenia (5), and hyponatremia (5). The overall response rate (ORR) in the efficacy-evaluable patients was $41 \%$ (7 of 17 ), all partial responses evaluated by RECIST version 1.1. Median overall survival (OS) was 7.0 months (1.8-41.7).
Conclusion. The defined recommended phase II dose (RPTD) was vinflunine $280 \mathrm{mg} / \mathrm{m}^{2}$ plus sorafenib $400 \mathrm{mg}$. Sorafenib was too toxic in combination with vinflunine $320 \mathrm{mg} / \mathrm{m}^{2}$. The ORR of $41 \%$ to this second-line combination treatment of mUC is noteworthy and supports further trials. The Oncologist 2019;24:745-e213

\section{Discussion}

For mUC patients with rapidly progressive platinumresistant disease, development of effective treatment options remains a challenge and an unmet medical need. The combination of vinflunine in standard dose plus doseescalated sorafenib was evaluated for safety and toxicity in this phase I trial in second-line treatment of mUC. All subjects had disease progression or relapse $\leq 6$ months following previous platinum-based chemotherapy, reflecting a cohort of patients with platinum-resistant disease.

The observed high rate of toxicity for patients treated with vinflunine of $320 \mathrm{mg} / \mathrm{m}^{2}$ is in line with previously reported 


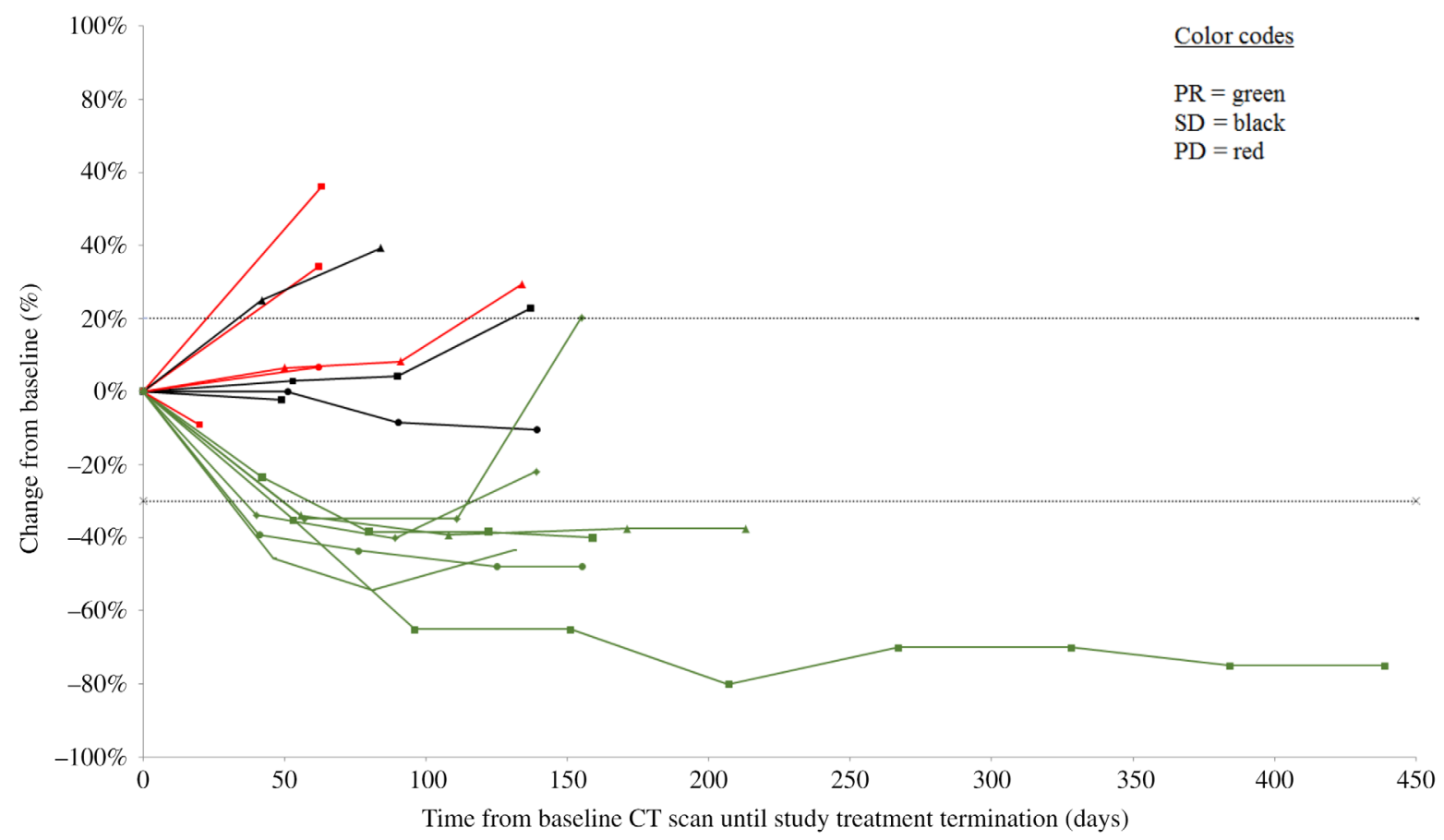

Figure 1. Tumor response by RECIST version 1.1. Percentage change in sum of the diameters of tumor lesions from baseline. Abbreviations: CT, computed tomography; PD, progressive disease; PR, partial response; SD, stable disease.

phase I vinflunine combination studies, including doublets with pazopanib and pemetrexed $[1,2]$. It appears as if fulldose vinflunine doublets for patients with platinumprogressive disease require combination with compounds with low bone marrow toxicity. Hence, the combination with sorafenib in this trial proved only to be safe and tolerable with a vinflunine starting dose of $280 \mathrm{mg} / \mathrm{m}^{2}$ [3-6]. The most frequent $A E$ grades $3+4$ in this study included neutropenia, hypertension, and hyponatremia. These side effects are potentially caused by both vinflunine and sorafenib, but more frequently reported in the former except for hypertension $[7,8]$.

The addition of sorafenib to vinflunine did not significantly improve median OS as compared with the vinflunine registration trial (7.0 vs. 6.9 months). For patients administered vinflunine $280 \mathrm{mg} / \mathrm{m}^{2}$ (e.g., Eastern Cooperative Oncology Group performance status [ECOG PS] 1, creatinine clearance $40-60 \mathrm{~mL} /$ minute) in this study, the prognosis was most likely even worse than for the average secondline patient treated within the vinflunine registration trial. Considering this fact, the observed ORR of $41 \%$ and disease control rate (DCR) of $71 \%$ in this study is notable, especially compared with the ORR and DCR of $8.6 \%$ and $55.1 \%$ in the vinflunine registration trial [3]. The higher response rates are plausibly attributable to the addition of sorafenib, possibly resulting in an additive effect of this specific drug combination. Further, the results of the present study are in line with the RANGE study, reporting an advantage of combining docetaxel with another vascular endothelial growth factor receptor 2 active compound, ramucirumab, thus adding evidence that selected platinum-refractory mUC patients may benefit from concomitant standard chemotherapy plus antiangiogenic targeted therapy [9].

Within the context of this phase I trial, an RPTD for the treatment combination of vinflunine and sorafenib was identified for $\mathrm{mUC}$ patients with platinum-resistant and progressive disease. The observed side effects were expected but with a higher incidence of grade $3+4$ hyponatremia than previously reported for vinflunine and sorafenib each administered as monotherapy. Clinically meaningful disease stabilization and objective responses were observed but with large differences in OS (Figs. 1 and 3). Future trials should aim to evaluate this treatment combination in a randomized setting, define biomarkers for treatment benefit, and explore the effects in patients with both platinum- and immunotherapy-resistant disease.

Trial Information

\begin{tabular}{ll} 
Disease & Bladder cancer \\
\hline Stage of Disease/Treatment & Metastatic/advanced \\
\hline Prior Therapy & One prior regimen \\
\hline Type of Study $-\mathbf{1}$ & Phase I \\
\hline Type of Study - 2 & $3+3$ \\
\hline Primary Endpoint & Maximum tolerated dose \\
\hline Primary Endpoint & Recommended phase II dose \\
\hline
\end{tabular}




\section{Additional Details of Endpoints or Study Design}

The Vinsor study was a phase I trial evaluating the treatment combination of standard-dose vinflunine and sorafenib, in dose escalation. Patients with progressive locally advanced mUC following platinum combination-chemotherapy were screened for inclusion at three cancer centers within the Nordic Urothelial Cancer Oncology Group collaboration, one center in Stockholm, Sweden, and two centers in Denmark, Copenhagen and Aarhus. The study was investigator-initiated and conducted as an academic clinical trial. The trial was monitored independently at the respective sites in Sweden and Denmark. The study was approved by the regional Ethical Review Board in Stockholm (October 12, 2011, ref 2011/1398-31/1) and by the Scientific Research Council Komité E, Region Hovedstaden, Hillerød, Denmark (August 28, 2012, ref H-1-2012-079). The study was approved by the Swedish Medical Products Agency (151:2012/12127) and by the Danish Health and Medicines Authority (2012053960). Study participation was compliant with the Declaration of Helsinki. Prior to screening procedures and treatment, signed informed consent was obtained from all patients. This trial is registered with ClinicalTrials.gov, number NCT01844947.

Eligibility Criteria: Eligible patients, aged 18-80 years, with ECOG PS 0 or 1, had a histologically confirmed diagnosis of UC (pure or mixed) of the urothelial tract. The major inclusion criteria stipulated that UC patients had a confirmed disease relapse or progression no later than at the 6-month follow-up visit after completion of previous platinum-based chemotherapy. Patients were not allowed to have received more than one previous line of chemotherapy treatment for locally advanced or mUC. Alternatively, patients with mUC and contraindication to platinum-containing chemotherapy were eligible. Any prior systemic chemotherapy needed to be permanently terminated 14 days prior to inclusion and recovery from treatment-related toxicity (grade 1 or less). Patients needed to have measurable or nonmeasurable disease using RECIST version 1.1. Patients with predominantly adenocarcinoma, squamous cell carcinoma, or any other nontransitional cell carcinoma were excluded. Prior treatment with vinflunine was not allowed. Patients with brain metastasis or leptomeningeal involvement were not eligible. Patients with congestive heart failure (New York Heart Association class $\geq 11$ ), angina pectoris, poorly controlled hypertension $>150 / 90 \mathrm{mmHg}$, hypercalcemia, hypokalemia, or QTc time $>450 \mathrm{~ms}$ at baseline were excluded. ECG controls were performed to exclude patients at high risk for developing arrhythmias. Included patients were required to have an acceptable hematologic function: hemoglobin $\geq 10 \mathrm{~g} / \mathrm{dL}$, absolute neutrophil count $\geq 1.0 \times$ lower limit of normal, and platelets $\geq 100000$ per $\mu \mathrm{L}$; adequate hepatic function: bilirubin <1.5X upper limit of normal (ULN), and transaminases $<2.5 \times$ ULN; renal function: creatinine clearance $\geq 40 \mathrm{~mL} /$ minute (measured by iohexol or ${ }^{51} \mathrm{Cr}$-EDTA techniques).

Procedures: The study subjects were treated with standard doses of vinflunine, 320 or $280 \mathrm{mg} / \mathrm{m}^{2}$, depending on their condition (see details below). In addition, patients were prescribed a fixed start dose of sorafenib $(400,600$, or $800 \mathrm{mg})$. Patients with ECOG PS 0 , age $\leq 74$ years, presenting adequate hepatic and renal function (defined as creatinine clearance $>60 \mathrm{~mL} / \mathrm{minute}$ ) were treated with vinflunine $320 \mathrm{mg} / \mathrm{m}^{2}$ intravenous (IV) on day 1 , and sorafenib in $200 \mathrm{mg}$ dose steps from 200 to $400 \mathrm{mg}$ b.i.d. on days $2-21$ every 3 weeks (Q3W). For patients with PS 1, or age 75-80 years, or previous exposure to radiation of the lower pelvic region, or with impaired renal function (creatinine clearance $40-60 \mathrm{~mL} /$ minute) but adequate hepatic function, the dose of vinflunine was $280 \mathrm{mg} / \mathrm{m}^{2} \mathrm{IV}$ on day $1 \mathrm{and}$ sorafenib as per above days 2-21, repeated every 21 days. Treatment continued until progression, unacceptable toxicity, or any other medical event requiring a stop. Pause in treatment was allowed for up to 14 days. Dose reductions were permitted as described in the protocol. Toxicity was graded according to the National Cancer Institute's Common Terminology Criteria for Adverse Events (CTCAE) version 4.0. Adverse events were evaluated during all treatment cycles for all patients. Study drug-related adverse events recorded during cycle 1 and 2 served to define dose-limiting toxicity (DLT) as hematological toxicity: grade $\geq 4$ neutropenia (absolute neutrophil count $<0.5 \times 10^{9}$ for $\geq 7$ days or $<0.1 \times 10^{9}$ for $\geq 3$ days), or febrile neutropenia of grade $\geq 3$ (absolute neutrophil count $<1.0 \times 10^{9}$ and temperature $\geq 38.5^{\circ} \mathrm{C}$ ), or platelet count $<25 \times 10^{9} / \mathrm{L}$ or thrombocytopenia with bleeding or requiring platelet transfusion; and nonhematological toxicity: liver toxicity (alanine aminotransferase or aspartate aminotransferase) of grade $\geq 3$ for $>7$ days, or any other grade $\geq 3$ major organ toxicity according to CTCAE v 4.0. Any AE had to resolve to grade $\leq 2$ within 14 days to continue study treatment. Tumor response was radiologically evaluated by computer tomography after completing every two treatment cycles. Evaluation of response to treatment was performed on measurable and/or nonmeasurable tumor lesions using RECIST v 1.1.

Safety Assessment: Examination by physician (including performance status [World Health Organization ECOG scale] and body weight) weekly during cycle one and thereafter prior to every new treatment cycle (i.e., every 3rd week). Complete blood counts, electrolytes, and renal and hepatic function prior to and at day 8 in every treatment cycle. All patients were followed-up by a oncology nurse at day 8 and 15 during all treatment cycles. Blood pressure was monitored weekly during the first two cycles and thereafter every 3rd week as long as the active treatment remained.

Investigator's Analysis

Active and should be pursued further

Drug Information

\section{Drug 1}

Generic/Working Name

Trade Name

Company Name

Drug Type

Drug Class

Dose

Route

Schedule of Administration
Vinflunine

Javlor

Pierre Fabre

Small molecule

Tubulin/Microtubules targeting agent

280 and $320 \mathrm{mg} / \mathrm{m}^{2}$

IV

Day 1, Q3W 
Drug 2

Generic/Working Name

Trade Name

Company Name

Drug Type

Drug Class

Dose

Route

Schedule of Administration
Sorafenib

Nexavar

Bayer Healthcare AG

Small molecule

Raf - BRAF

400,600 , or 800 per day $(200+200,200+400$, or $400+400)$ $\mathrm{mg}$ per flat dose

p.o.

Morning and evening (b.i.d.) on days 2-21, Q3W

\begin{tabular}{|c|c|c|c|c|}
\hline Dose level & $\begin{array}{l}\text { Dose of drug: } \\
\text { vinflunine, } \mathrm{mg} / \mathrm{m}^{2}\end{array}$ & Dose of drug: sorafenib, $\mathrm{mg}$ & Number enrolled & Number evaluable for toxicity \\
\hline IA & 320 & 400 & 5 & 5 \\
\hline IB & 280 & 400 & 5 & 3 \\
\hline IIB & 280 & 600 & 6 & 6 \\
\hline IIIB & 280 & 800 & 6 & 5 \\
\hline
\end{tabular}

Patient Characteristics

Number of Patients, Male

13

Number of Patients, Female

9

Stage

Metastatic urothelial cancer (all patients)

Age

Median (range): 62.5 years, range $44-71$ years

Number of Prior Systemic Therapies

Median (range): 1, range 1-1

Performance Status: ECOG

$$
\begin{aligned}
& 0-9 \\
& 1-13 \\
& 2-0 \\
& 3-0 \\
& \text { Unknown }-0
\end{aligned}
$$

\section{Other}

Previous treatments included cystectomy (10 patients) and nephrectomy/ureterectomy (3). No previous surgery (9). No patient had received radiation to the pelvic region prior to study inclusion. All patients had received one line of platinum (cisplatin or carboplatin)-containing systemic chemotherapy treatment (median 5 cycles [range 1-11]).

Cancer Types or Histologic Subtypes

Urothelial tract cancer (urothelial histology) ICD-10: C66.9-C68.9

\section{Primary Assessment Method}

Title

Number of Patients Screened

Number of Patients Enrolled

Number of Patients Evaluable for Toxicity

Number of Patients Evaluated for Efficacy

Evaluation Method

Response Assessment CR

Response Assessment PR

Response Assessment SD

Response Assessment PD

Response Assessment OTHER

(Median) Duration Assessments PFS

(Median) Duration Assessments TTP

(Median) Duration assessments OS

(Median) Duration Assessments Duration of Treatment

\section{Efficacy assessment}

69

22

19

17

RECIST 1.1

$n=0(0 \%)$

$n=7(41 \%)$

$n=5(29 \%)$

$n=5(29 \%)$

$n=0(0 \%)$

4.5 months

4.2 months

7.0 months

2.3 months 


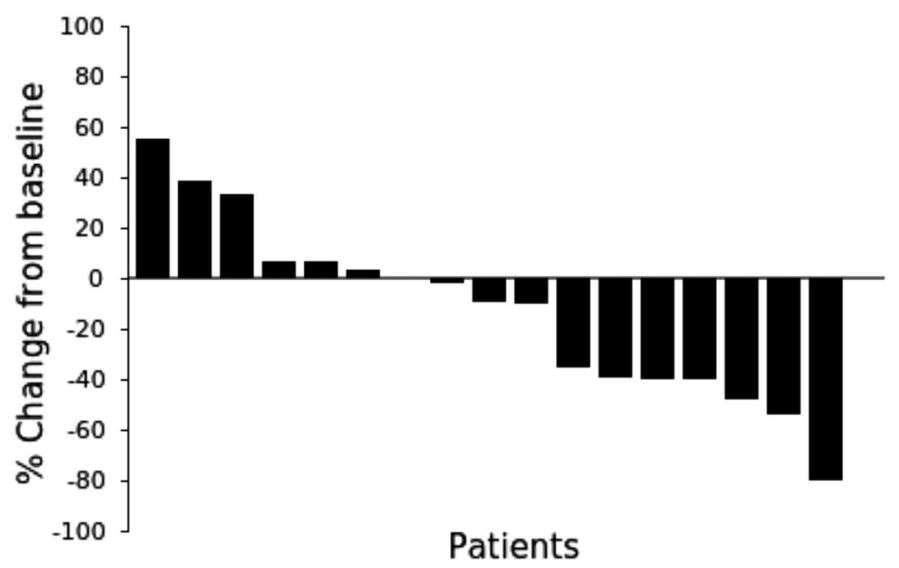

Figure 2. Waterfall plot of individual patient's tumor response by RECIST version 1.1. Best percentage change in the sum of size (diameters) of tumor lesions from baseline until the end of study treatment. One patient (number 17) developed brain metastases (new nontarget tumor lesions) during cycle 2. No formal treatment evaluation of this patient's target lesions was performed.

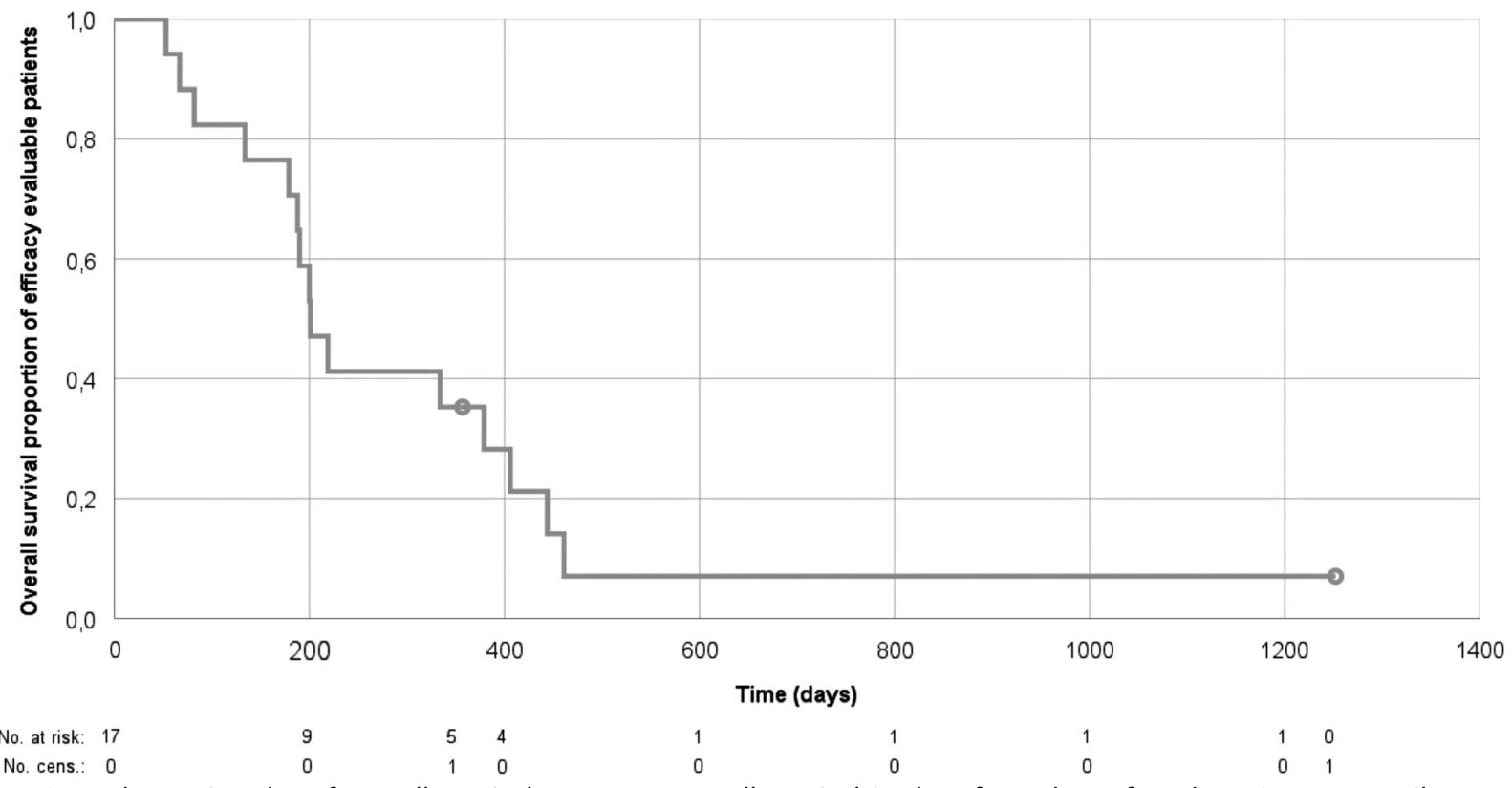

Figure 3. Kaplan-Meier plot of overall survival outcome. Overall survival in days from date of study assignment until recorded death among the efficacy-evaluable patients $(n=17)$.

$\begin{array}{llllll}\begin{array}{l}\text { KaPLAN-Meier Time Units } \\ \text { Days }\end{array} & & & & \\ \begin{array}{l}\text { Time of scheduled assessment } \\ \text { and/or time of event }\end{array} & \begin{array}{l}\text { No. progressed } \\ \text { (or deaths) }\end{array} & \begin{array}{l}\text { No. } \\ \text { censored }\end{array} & \begin{array}{l}\text { Percent at start of } \\ \text { evaluation period }\end{array} & \begin{array}{l}\text { Kaplan- } \\ \text { Meier \% }\end{array} & \begin{array}{l}\text { No. at next } \\ \text { evaluation/No. } \\ \text { at risk }\end{array} \\ 0 & 0 & 0 & 100.00 & 100.00 & 17 \\ 53 & 1 & 0 & 100.00 & 94.12 & 16 \\ 67 & 1 & 0 & 94.12 & 88.24 & 15 \\ 82 & 1 & 0 & 88.24 & 82.35 & 14 \\ 134 & 1 & 0 & 82.35 & 76.47 & 13 \\ 179 & 1 & 0 & 76.47 & 70.59 & 12 \\ 188 & 1 & 0 & 70.59 & 64.71 & 11\end{array}$




$\begin{array}{lllllll}190 & 1 & 0 & 64.71 & 58.82 & 10 \\ 200 & 1 & 0 & 58.82 & 52.94 & 9 & 8 \\ 201 & 1 & 0 & 52.94 & 47.06 & 7 & \\ 219 & 1 & 0 & 47.06 & 41.18 & 75.29 & 6 \\ 334 & 1 & 0 & 41.18 & 35.29 & 5 \\ 357 & 0 & 1 & 35.29 & 28.24 & 4 \\ 379 & 1 & 0 & 35.29 & 21.18 & 3 \\ 406 & 1 & 0 & 28.24 & 14.12 & 2 \\ 444 & 1 & 0 & 21.18 & 7.06 & 1 \\ 461 & 1 & 0 & 14.12 & 0.00 & 0\end{array}$

\section{Outcome Notes:}

Sixty-nine patients were screened for inclusion between April 2012 and September 2017. Screening failures included no progression on platinum within 6 months, comorbidity or insufficient PS, second-line treatment previously administered, history of other malignancy, and prolonged QTc interval. Twenty-two patients at three sites in two countries were included. The primary tumor was located in the bladder (18 patients), renal pelvis ( 2 patients), and ureter ( 2 patients). All included patients had confirmed histology of pure urothelial carcinoma at inclusion and disease progression within 6 months following treatment with platinum and gemcitabine. Previous surgical treatment included cystectomy in 10 patients and nephrectomy/ureterectomy in 3 patients. The median number of cycles administered was 4 (range 1-16). Median duration of study treatment was 4.1 months (0.1-14.5) among the DLT-evaluable patients. The MTD of vinflunine $320 \mathrm{mg} / \mathrm{m}^{2}$ day 1 with sorafenib days $2-21$ Q3W was not defined $(<400 \mathrm{mg}$ ) because three out of five patients had a DLT in the first dose cohort. For patients treated with vinflunine $320 \mathrm{mg} / \mathrm{m}^{2}$, adding sorafenib, even at a dose of $400 \mathrm{mg}$ daily, resulted in unacceptable toxicity. The MTD of vinflunine $280 \mathrm{mg} / \mathrm{m}^{2}$ day 1 with sorafenib was $600 \mathrm{mg}(200+400 \mathrm{mg})$ days 2-21 Q3W. Five of eight patients with treatment-induced hypertension received at least six cycles of treatment, and three partial responses were reported. Two of the six efficacy-evaluable patients with skin rash had a partial response and three had stable disease on study treatment. Two patients continued with vinflunine monotherapy after study completion. Three patients received experimental treatment within clinical trial protocols and two patients received immunotherapy. At data cutoff date, October 1, 2018, two patients remained alive.

\begin{tabular}{|c|c|c|c|c|c|c|c|}
\hline \multicolumn{8}{|l|}{ All Cycles } \\
\hline Name & NC/NA & 1 & 2 & 3 & 4 & 5 & All grades \\
\hline Febrile neutropenia & $73 \%$ & $0 \%$ & $0 \%$ & $16 \%$ & $11 \%$ & $0 \%$ & $27 \%$ \\
\hline Neutrophil count decreased & $63 \%$ & $0 \%$ & $5 \%$ & $16 \%$ & $16 \%$ & $0 \%$ & $37 \%$ \\
\hline Platelet count decreased & $90 \%$ & $0 \%$ & $5 \%$ & $5 \%$ & $0 \%$ & $0 \%$ & $10 \%$ \\
\hline Anemia & $70 \%$ & $10 \%$ & $20 \%$ & $0 \%$ & $0 \%$ & $0 \%$ & $30 \%$ \\
\hline Palpitations & $95 \%$ & $5 \%$ & $0 \%$ & $0 \%$ & $0 \%$ & $0 \%$ & $5 \%$ \\
\hline Hypertension & $53 \%$ & $0 \%$ & $26 \%$ & $21 \%$ & $0 \%$ & $0 \%$ & $47 \%$ \\
\hline Gum infection & $68 \%$ & $16 \%$ & $16 \%$ & $0 \%$ & $0 \%$ & $0 \%$ & $32 \%$ \\
\hline Diarrhea & $58 \%$ & $37 \%$ & $5 \%$ & $0 \%$ & $0 \%$ & $0 \%$ & $42 \%$ \\
\hline Oral pain & $89 \%$ & $11 \%$ & $0 \%$ & $0 \%$ & $0 \%$ & $0 \%$ & $11 \%$ \\
\hline Dysgeusia & $95 \%$ & $5 \%$ & $0 \%$ & $0 \%$ & $0 \%$ & $0 \%$ & $5 \%$ \\
\hline Dyspepsia & $95 \%$ & $5 \%$ & $0 \%$ & $0 \%$ & $0 \%$ & $0 \%$ & $5 \%$ \\
\hline Constipation & $40 \%$ & $5 \%$ & $55 \%$ & $0 \%$ & $0 \%$ & $0 \%$ & $60 \%$ \\
\hline Vomiting & $68 \%$ & $16 \%$ & $16 \%$ & $0 \%$ & $0 \%$ & $0 \%$ & $32 \%$ \\
\hline Nausea & $57 \%$ & $32 \%$ & $11 \%$ & $0 \%$ & $0 \%$ & $0 \%$ & $43 \%$ \\
\hline Dizziness & $84 \%$ & $11 \%$ & $5 \%$ & $0 \%$ & $0 \%$ & $0 \%$ & $16 \%$ \\
\hline Weight gain & $95 \%$ & $5 \%$ & $0 \%$ & $0 \%$ & $0 \%$ & $0 \%$ & $5 \%$ \\
\hline Anorexia & $95 \%$ & $5 \%$ & $0 \%$ & $0 \%$ & $0 \%$ & $0 \%$ & $5 \%$ \\
\hline Weight loss & $90 \%$ & $5 \%$ & $5 \%$ & $0 \%$ & $0 \%$ & $0 \%$ & $10 \%$ \\
\hline Blood bilirubin increased & $95 \%$ & $5 \%$ & $0 \%$ & $0 \%$ & $0 \%$ & $0 \%$ & $5 \%$ \\
\hline Hyponatremia & $74 \%$ & $0 \%$ & $0 \%$ & $21 \%$ & $5 \%$ & $0 \%$ & $26 \%$ \\
\hline
\end{tabular}




\begin{tabular}{|c|c|c|c|c|c|c|c|}
\hline Hypokalemia & $90 \%$ & $5 \%$ & $5 \%$ & $0 \%$ & $0 \%$ & $0 \%$ & $10 \%$ \\
\hline Headache & $90 \%$ & $5 \%$ & $5 \%$ & $0 \%$ & $0 \%$ & $0 \%$ & $10 \%$ \\
\hline Fatigue & $20 \%$ & $35 \%$ & $35 \%$ & $10 \%$ & $0 \%$ & $0 \%$ & $80 \%$ \\
\hline Peripheral sensory neuropathy & $78 \%$ & $11 \%$ & $11 \%$ & $0 \%$ & $0 \%$ & $0 \%$ & $22 \%$ \\
\hline Dry skin & $84 \%$ & $16 \%$ & $0 \%$ & $0 \%$ & $0 \%$ & $0 \%$ & $16 \%$ \\
\hline Alopecia & $84 \%$ & $11 \%$ & $5 \%$ & $0 \%$ & $0 \%$ & $0 \%$ & $16 \%$ \\
\hline Palmar-plantar erythrodysesthesia syndrome & $79 \%$ & $16 \%$ & $5 \%$ & $0 \%$ & $0 \%$ & $0 \%$ & $21 \%$ \\
\hline $\begin{array}{l}\text { Skin and subcutaneous tissue } \\
\text { disorders - rash/desquamation }\end{array}$ & $65 \%$ & $15 \%$ & $20 \%$ & $0 \%$ & $0 \%$ & $0 \%$ & $35 \%$ \\
\hline Urinary tract infection & $95 \%$ & $0 \%$ & $5 \%$ & $0 \%$ & $0 \%$ & $0 \%$ & $5 \%$ \\
\hline Urinary frequency & $95 \%$ & $5 \%$ & $0 \%$ & $0 \%$ & $0 \%$ & $0 \%$ & $5 \%$ \\
\hline Myalgia & $80 \%$ & $15 \%$ & $5 \%$ & $0 \%$ & $0 \%$ & $0 \%$ & $20 \%$ \\
\hline Abdominal pain & $95 \%$ & $0 \%$ & $5 \%$ & $0 \%$ & $0 \%$ & $0 \%$ & $5 \%$ \\
\hline Pelvic pain & $95 \%$ & $5 \%$ & $0 \%$ & $0 \%$ & $0 \%$ & $0 \%$ & $5 \%$ \\
\hline Injection site reaction & $95 \%$ & $5 \%$ & $0 \%$ & $0 \%$ & $0 \%$ & $0 \%$ & $5 \%$ \\
\hline Dyspnea & $85 \%$ & $5 \%$ & $5 \%$ & $5 \%$ & $0 \%$ & $0 \%$ & $15 \%$ \\
\hline Ileus & $90 \%$ & $0 \%$ & $5 \%$ & $5 \%$ & $0 \%$ & $0 \%$ & $10 \%$ \\
\hline Edema limbs & $95 \%$ & $5 \%$ & $0 \%$ & $0 \%$ & $0 \%$ & $0 \%$ & $5 \%$ \\
\hline Thromboembolic event & $84 \%$ & $0 \%$ & $11 \%$ & $0 \%$ & $0 \%$ & $5 \%$ & $16 \%$ \\
\hline Abdominal infection & $95 \%$ & $0 \%$ & $0 \%$ & $5 \%$ & $0 \%$ & $0 \%$ & $5 \%$ \\
\hline Urinary tract obstruction & $95 \%$ & $0 \%$ & $5 \%$ & $0 \%$ & $0 \%$ & $0 \%$ & $5 \%$ \\
\hline Back pain & $95 \%$ & $0 \%$ & $5 \%$ & $0 \%$ & $0 \%$ & $0 \%$ & $5 \%$ \\
\hline Nervous system disorders - Dysesthesia & $95 \%$ & $0 \%$ & $5 \%$ & $0 \%$ & $0 \%$ & $0 \%$ & $5 \%$ \\
\hline Palmar-plantar erythrodysesthesia syndrome & $95 \%$ & $0 \%$ & $5 \%$ & $0 \%$ & $0 \%$ & $0 \%$ & $5 \%$ \\
\hline Hypothyroidism & $100 \%$ & $0 \%$ & $0 \%$ & $0 \%$ & $0 \%$ & $0 \%$ & $0 \%$ \\
\hline
\end{tabular}

Number of cases that reported adverse events and grade of adversity as defined by National Cancer Institute Common Terminology Criteria for Adverse Events version 4.0. Three patients did not complete the initial two treatment cycles and were not diagnosed with a dose-limiting toxicity, hence the variation in $n$.

Abbreviation: NC/NA, no change from baseline/no adverse event.

\section{Serious Adverse Events}

\begin{tabular}{lll} 
Name & Grade & Attribution \\
Subileus & 3 & Unlikely \\
Malnutrition & 2 & Unlikely \\
Febrile neutropenia (DLT) & 4 & Definite \\
\hline Pain & 2 & Probable \\
Ileus & 3 & Unrelated \\
\hline Deep vein thrombosis & 2 & Unrelated \\
Dyspnea & 3 & Unrelated \\
\hline Dyspnea & 2 & Unrelated \\
Constipation & 2 & Probable \\
\hline Urinary obstruction (nephrostomy) & Unrelated \\
Febrile neutropenia (DLT) & 2 & Definite \\
Hypertension (DLT) & 3 & Definite \\
Fever & 3 & Probable \\
\hline Febrile neutropenia (DLT) & 1 & Definite \\
Constipation & 3 & Probable \\
\hline Fever & 2 & Unrelated \\
Deep vein thrombosis & 2 & Unlikely \\
\hline Ileus & 3 & Unlikely \\
Abdominal pain & 2 & Unlikely \\
\hline
\end{tabular}




$\begin{array}{llc}\text { Pulmonary embolism } & 5 & \text { Unlikely } \\ \text { Abdominal abscess } & 3 & \text { Unrelated } \\ \text { Febrile neutropenia (DLT) } & 4 & \text { Definite } \\ \text { Febrile neutropenia (DLT) } & 3 & \text { Definite } \\ \text { Neutropenia (DLT) } & 4 & \text { Definite }\end{array}$

Attribution (if not identical relation to sorafenib and vinflunine): febrile neutropenia (DLT) G4 - definite vinflunine (sorafenib: unlikely), pain G2 - probable vinflunine (sorafenib: not related), constipation G2 - probable vinflunine (sorafenib: unlikely) $\times 2$, febrile neutropenia (DLT) G3 - definite vinflunine (sorafenib: probable) $\times 2$, neutropenia (DLT) G4 - definite vinflunine (sorafenib: unlikely), hypertension (DLT) G3 - definite sorafenib (vinflunine: not related). Abbreviation: DLT, dose-limiting toxicity.

\section{Dose-Limiting Toxicities}

$\begin{array}{lllll}\begin{array}{l}\text { Dose } \\ \text { level }\end{array} & \begin{array}{l}\text { Number } \\ \text { enrolled }\end{array} & \begin{array}{l}\text { Number evaluable for } \\ \text { toxicity }\end{array} & \begin{array}{l}\text { Number with a dose-limiting } \\ \text { toxicity }\end{array} & \begin{array}{l}\text { Dose-limiting toxicity } \\ \text { information }\end{array} \\ \text { IA } & 5 & 5 & 3 & \begin{array}{l}\text { Febrile neutropenia } \times 2, \\ \text { hypertension }\end{array} \\ \text { IB } & 5 & 3 & 0 & \\ \text { IIB } & 6 & 6 & 1 & \text { Febrile neutropenia } \\ \text { IIIB } & 6 & 5 & 3 & \begin{array}{l}\text { Febrile neutropenia } \times 2, \\ \text { neutropenia }\end{array}\end{array}$

Assessment, Analysis, and Discussion

\section{Completion}

Investigator's Assessment

Although the recently approved immunotherapies can induce impressive and durable responses, the majority of patients with metastatic urothelial cancer (mUC) do not have major responses. In the randomized second-line phase III trial of pembrolizumab, the overall response rate (ORR) was limited to $21.1 \%$, and the response rates reported for atezolizumab, durvalumab, avelumab, and nivolumab are in the same range [10-14]. For these postimmunotherapy patients, as well as for patients with rapidly progressive platinumresistant disease, further development of effective treatment options remains a challenge and an unmet medical need.

The combination of vinflunine in standard dose with doseescalated sorafenib was evaluated for safety and toxicity in this phase I trial for patients with mUC. All included patients in this study had disease progression or relapse within 6 months following previous platinum-based chemotherapy, reflecting a cohort of typically platinum-resistant patients with aggressive disease.

The observed high rate of toxicity for patients treated with a start dose of vinflunine of $320 \mathrm{mg} / \mathrm{m}^{2}$ is in line with previously reported phase I vinflunine combination studies, including doublets with pazopanib and pemetrexed $[1,2]$. It appears as if full-dose vinflunine doublets for patients with progressive disease after cisplatin requires combination compounds with low bone marrow toxicity. Hence, the combination with sorafenib proved only to be safe and tolerable with a vinflunine start dose of $280 \mathrm{mg} / \mathrm{m}^{2}$. Side effects of grade 1 and 2 were mainly gastrointestinal (constipation and diarrhea), fatigue, nausea/vomiting, and skin rash. Constipation and pain have more commonly been reported with vinflunine, whereas diarrhea is frequently seen with tyrosine kinase inhibitor therapies and fatigue with either [3-6]. The top three reported adverse events (AEs) of grade $\geq 3$ in this study
Study completed

Active and should be pursued further

included neutropenia (31.6\%), hyponatremia (26.3\%), and febrile neutropenia (26.3\%). These side effects are potentially caused by both vinflunine and sorafenib, but are more frequent in the former except for hypertension $[7,8]$. No definite treatment-related death was recorded, but one patient had fatal pulmonary embolism (unlikely relation to study treatment). Overall, the AEs are in line with previous studies combining vinflunine and other cytotoxic agents $[1,2,15]$.

The addition of sorafenib to vinflunine did not improve median overall survival (OS) as compared with the registration trial by Bellmunt et al. evaluating monotherapy with vinflunine with best supportive care (BSC) versus BSC alone (7.0 vs. 6.9 months). For the cohort of patients receiving the vinflunine start dose of $280 \mathrm{mg} / \mathrm{m}^{2}$ (e.g., Eastern Cooperative Oncology Group performance status 1, creatinine clearance 40-60 $\mathrm{mL} /$ minute), and in which the recommended phase II dose (RPTD) was defined, the prognosis is, however, most likely even worse than for the average second-line patient treated within the vinflunine registration trial [3]. In this view, the observed ORR of $41 \%$ and DCR of $71 \%$ in this study of platinumrefractory $\mathrm{mUC}$ is notable, especially compared with the ORR and DCR of $8.6 \%$ and $55.1 \%$ in the vinflunine phase III trial, and $16 \%-18 \%$ and $57 \%-67 \%$, respectively, in previous phase II trials $[3,16,17]$. It can be speculated that the reduction of metastatic tumor burden and stabilization of disease could translate into clinical meaningful palliation and increased quality of life for some $\mathrm{mUC}$ patients with otherwise aggressive disease and few treatment options. Interestingly, both rash and hypertension, two side effects correlated with treatment benefit in renal cell carcinoma, were common in patients with partial response or disease stabilization. The favorable overall response rates in this study are plausibly attributable to the addition of sorafenib to 
vinflunine, possibly resulting in an additive effect of this specific drug combination. Further, the results of the present study are in line with the recently reported outcome of the RANGE study, reporting an advantage of combining docetaxel with another vascular endothelial growth factor receptor 2 active compound, ramucirumab, thus adding evidence that patients with platinum-refractory mUC may benefit from combined treatment with standard chemotherapy and antiangiogenic targeted therapy [9]. Nevertheless, the overall positive response rate of this trial could still be at random considering the limited size and phase I design. In comparison, a phase II randomized study of gemcitabine and cisplatin plus sorafenib or placebo in firstline mUC resulted in an ORR of $52.5 \%$ and DCR of $75 \%$ versus $50 \%$ and $79 \%$, showing no additional response effect of sorafenib [18]. If this trial could be repeated, eligible patients would include those with relapse within 12 months of platinumcontaining systemic treatment, thus increasing inclusion rate. Future trials should aim to evaluate this treatment combination in a randomized setting, define biomarkers for treatment benefit, and explore the effects in patients with both platinum- and immunotherapy-resistant disease.

Within the context of this phase I trial, a RPTD for the treatment combination of vinflunine and sorafenib was identified for mUC patients with platinum-resistant and progressive disease. The observed side effects were as expected and reversible but with a higher incidence of grade 3 and 4 hyponatremia than previously reported for vinflunine and sorafenib administered as monotherapy. Clinically meaningful disease stabilization and objective responses were observed in a number of patients with poor prognosis along with interindividual variation in OS.

\section{ACKNOWLEDGMENTS}

We are grateful for the administrative help of the clinical trial support staff at all three sites. We are thankful for the financial support provided by the Swedish Cancer Society, the Stockholm Cancer Society, Stockholm County Council, Pierre Fabre Pharma Norden $A B$, and Bayer Healthcare AG, who also provided sorafenib free of charge.

\section{DisclosuRES}

Carl-Henrik Shah: Pierre Fabre Pharma Norden AB, Bayer

Healthcare AG (RF); Helle Pappot: Merck Sharpe \& Dohme, Roche (RF); Karin Holmsten: Pierre Fabre Pharma (RF, study/meeting expenses); Anders Ullén: Pierre Fabre Pharma (C/A), Pierre Fabre Pharma, Bayer (RF, study/meeting expenses). The other authors indicated no financial relationships.

(C/A) Consulting/advisory relationship; (RF) Research funding; (E) Employment; (ET) Expert testimony; (H) Honoraria received; (OI) Ownership interests; (IP) Intellectual property rights/ inventor/patent holder; (SAB) Scientific advisory board

\section{REFERENCES}

1. Gerullis $\mathrm{H}$, Eimer $\mathrm{C}$, Ecke TH et al. Combined treatment with pazopanib and vinflunine in patients with advanced urothelial carcinoma refractory after first-line therapy. Anticancer Drugs 2013;24:422-425.

2. Pappot $H$, von der Maase $H$, Ullen $A$ et al. Combined treatment with pemetrexed and vinflunine in patients with metastatic urothelial cell carcinoma after prior platinum-containing chemotherapy - results of an exploratory phase I study. Invest New Drugs 2018;36:615-618.

3. Bellmunt J, Theodore C, Demkov $T$ et al. Phase III trial of vinflunine plus best supportive care compared with best supportive care alone after a platinum-containing regimen in patients with advanced transitional cell carcinoma of the urothelial tract. J Clin Oncol 2009;27:4454-4461.

4. Escudier B, Szczylik C, Hutson TE et al. Randomized phase II trial of first-line treatment with sorafenib versus interferon Alfa-2a in patients with metastatic renal cell carcinoma. J Clin Oncol 2009;27:1280-1289.

5. Brose MS, Nutting CM, Jarzab B et al. Sorafenib in radioactive iodine-refractory, locally advanced or metastatic differentiated thyroid cancer: A randomised, double-blind, phase 3 trial. Lancet 2014;384:319-328.

6. Llovet JM, Ricci S, Mazzaferro V et al. Sorafenib in advanced hepatocellular carcinoma. N Engl J Med 2008;359:378-390.
7. Summary of Product Characteristics - Javlor dated 30/07/2014. Available at ema.europa.eu. Accessed October 2, 2018.

8. Summary of Product Characteristics - Nexavar dated 30/09/2016. Available at ema.europa. eu. Accessed October 2, 2018.

9. Petrylak DP, de Wit R, Chi KN et al. Ramucirumab plus docetaxel versus placebo plus docetaxel in patients with locally advanced or metastatic urothelial carcinoma after platinumbased therapy (RANGE): A randomised, doubleblind, phase 3 trial. Lancet 2017;390:2266-2277.

10. Bellmunt J, de Wit R, Vaughn DJ et al. Pembrolizumab as second-line therapy for advanced urothelial carcinoma. N Engl J Med 2017;376: 1015-1026.

11. Patel MR, Ellerton J, Infante JR et al. Avelumab in metastatic urothelial carcinoma after platinum failure (JAVELIN Solid Tumor): Pooled results from two expansion cohorts of an openlabel, phase 1 trial. Lancet Oncol 2018;19:51-64.

12. Powles $T$, O'Donnell PH, Massard $C$ et al. Efficacy and safety of durvalumab in locally advanced or metastatic urothelial carcinoma: Updated results from a phase $1 / 2$ open-label study. JAMA Oncol 2017;3:e172411.

13. Rosenberg JE, Hoffman-Censits J, Powles $T$ et al. Atezolizumab in patients with locally advanced and metastatic urothelial carcinoma who have progressed following treatment with platinum-based chemotherapy: A single-arm, multicentre, phase 2 trial. Lancet 2016;387: 1909-1920.

14. Sharma $P$, Retz $M$, Siefker-Radtke $A$ et al. Nivolumab in metastatic urothelial carcinoma after platinum therapy (CheckMate 275): A multicentre, single-arm, phase 2 trial. Lancet Oncol 2017;18:312-322.

15. De Santis M, Wiechno PJ, Bellmunt J et al. Vinflunine-gemcitabine versus vinfluninecarboplatin as first-line chemotherapy in cisplatinunfit patients with advanced urothelial carcinoma: results of an international randomized phase II trial (JASINT1). Ann Oncol 2016;27:449-454.

16. Culine S, Theodore $C$, De Santis $M$ et al. A phase II study of vinflunine in bladder cancer patients progressing after first-line platinumcontaining regimen. $\mathrm{Br} J$ Cancer 2006;94:1395-1401.

17. Vaughn DJ, Srinivas $S$, Stadler WM et al. Vinflunine in platinum-pretreated patients with locally advanced or metastatic urothelial carcinoma: Results of a large phase 2 study. Cancer 2009;115:4110-4117.

18. Krege $\mathrm{S}$, Rexer $\mathrm{H}$, vom Dorp $\mathrm{F}$ et al. Prospective randomized double-blind multicentre phase II study comparing gemcitabine and cisplatin plus sorafenib chemotherapy with gemcitabine and cisplatin plus placebo in locally advanced and/or metastasized urothelial cancer: SUSE (AUO-AB 31/05). BJU Int 2014;113: 429-436. 


\section{TABLE}

Table 1. Baseline characteristics, including previous treatment and prognostic factors

\begin{tabular}{|c|c|}
\hline Characteristic & $\begin{array}{l}\text { All patients } \\
(n=22), n(\%)\end{array}$ \\
\hline Median age, years (range) & $62.5(44-71)$ \\
\hline \multicolumn{2}{|l|}{ Sex } \\
\hline Men & $13(59)$ \\
\hline Women & $9(41)$ \\
\hline \multicolumn{2}{|l|}{ ECOG PS } \\
\hline 0 & $9(41)$ \\
\hline 1 & $13(59)$ \\
\hline \multicolumn{2}{|l|}{ Previous treatments } \\
\hline Cystectomy & $10(45)$ \\
\hline Nephrectomy/ureterectomy & $3(14)$ \\
\hline No surgery & $9(41)$ \\
\hline Radiation to pelvic region & $0(0)$ \\
\hline No radiation to pelvic region & $22(100)$ \\
\hline $\begin{array}{l}\text { Neoadjuvant cisplatin and } \\
\text { gemcitabine }\end{array}$ & $6(27)$ \\
\hline Adjuvant cisplatin and gemcitabine ${ }^{a}$ & $2(9)$ \\
\hline Palliative cisplatin and gemcitabine ${ }^{a}$ & $13(59)$ \\
\hline $\begin{array}{l}\text { Palliative carboplatin and } \\
\text { gemcitabine }\end{array}$ & $3(14)$ \\
\hline \multicolumn{2}{|l|}{$\begin{array}{l}\text { Previous platinum and gemcitabine } \\
\text { treatment cycles }\end{array}$} \\
\hline$\geq 6$ & $9(41)$ \\
\hline $2-5$ & $12(55)$ \\
\hline 1 & $1(5)$ \\
\hline \multicolumn{2}{|l|}{ Hemoglobin, g/L } \\
\hline$\geq 120$ & $9(41)$ \\
\hline 100-119 & $12(55)$ \\
\hline$<100$ & $1(5)$ \\
\hline \multicolumn{2}{|l|}{ Liver metastasis } \\
\hline Yes & $6(27)$ \\
\hline No & $16(73)$ \\
\hline
\end{tabular}

Click here to access other published clinical trials. 